\title{
LOS "ENVUELTOS" DE BAÑOS COMO PATRIMONIO GASTRONÓMICO DE CUENCA (ECUADOR)
}

\author{
The "envueltos" of baños as a gastronomic heritage of Cuenca (Ecuador) \\ Miguel Ángel Novillo Verdugo \\ Universidad de Cuenca, Ecuador \\ miguel.novillo@ucenca.edu.ec \\ Elsa Rosario Sinchi Lojano \\ Centro de Estudios Socioculturales, CERES, Ecuador \\ elsarosariosinchi@gmail.com
}

Recibido: $18-08-2018$

Aprobado: 28-09-2018

Miguel Ángel Novillo Verdugo es
Licenciado en Historia
(Universidad de Cuenca) y
Maestro en Arqueología por el
Colegio de Michoacán, A. C.
(México). Su línea de
investigación se centra en el
estudio de las bebidas
fermentadas prehispánicas de
América. Actualmente, realiza
investigaciones arqueológicas en
la región sur de Ecuador, donde
es docente de la Universidad de
Cuenca y miembro del Programa
de Escritura y Lectura
Académicas, Killkana.
Elsa Rosario Sinchi Lojano es
Maestrante en Antropología de lo
Contemporáneo (Universidad de
Cuenca) y Especialista en Historia
(Universidad Andina Simón
Bolívar). Sus estudios de
pregrado los realizó en la
Universidad de Cuenca, carrera
de Historia y Geografía. Ha estado
vinculada a proyectos de

\section{RESUMEN}

Baños es una parroquia rural de Cuenca (Ecuador) culturalmente diversa donde, de forma paulatina, sus prácticas y tradiciones se transforman o desaparecen, generando olvido, pérdida y ausencia de identidad. De esta manera, es necesario registrar y traer a la actualidad ciertos hechos que forman parte de la historia local, partiendo del estudio de los denominados envueltos (timbulos, chaquis, humas y tamales) y su relación directa con la cocina, la gastronomía y la alimentación como componente de la memoria y el patrimonio. Para tal efecto, se realizaron entrevistas a las actoras de estas actividades, quienes por medio de la memoria y la oralidad nos dan cuenta de ese pasado.

Palabras clave: envueltos; cocina; gastronomia; memoria; patrimonio

\section{ABSTRACT}

Baños is a culturally diverse rural parish of Cuenca (Ecuador) where, gradually, its practices and traditions are chaning or disappearing, generating oblivion, loss, and absence of identity. Thus, it is necessary to register and bring to the present certain events that are part of the local history, starting from the study of the so called 'envueltos' (timbulos, chaquis, humas y tamales) and their direct relationship with cooking, gastronomy and food as a component of memory and heritage. For such purpose, interviews were carried out with the actors of these activities, who give us an account of the past through memory and oral tradition. 
investigación con el Instituto Nacional de Patrimonio y Cultura (INPC). Es miembro-investigador del Centro Regional de Estudios Socioculturales (CERES). Sus líneas de investigación están enfocadas en Historia Social y Cultural, Antropología y Patrimonio.
Keywords: envueltos; cooking; gastronomy; memory; heritage

\section{Introducción: Baños y su memoria gastronómica}

El Ecuador, y la ciudad de Cuenca específicamente, constituyen centros de manifestaciones culturales donde prima la gastronomía -tomando en consideración su trayectoria histórica, medios geográficos y tradiciones populares-. Este aspecto cultural y nutricio se expresa en una variedad de recursos que pueden ser manipulados y transformados para obtener alimentos, como por ejemplo el maíz, que es la base de la dieta en diferentes ámbitos y regiones...

\footnotetext{
Con harina de maíz se elaboran tortillas, panes, tamales, quimbolitos, chigüiles, champús, y en el día de difuntos, se acostumbra la colada morada o mazamorra con harina de maíz negro endulzada con miel y compuesto con jugos de mora, naranjilla, mortiño. La chicha de jora se obtiene del maíz germinado, molido y secado al sol. La humita y las torrijas se confeccionan con maíz tierno y molido... (Pazos, 2017: 31)
}

Bajo este contexto se configura lo que se denomina cocina tradicional como componente de la cultura popular-rasgos que definen la identidad colectiva de una determinada zona-, convirtiendo a la comida y a las relaciones que giran en torno a esta como parte de la construcción de la identidad cultural (López García en Naranjo, 2005). Y como tal, representan elementos propensos al cambio, a la transformación, la variación y la presentación pues, se reconocen, por lo menos, dos niveles de preparación: uno cotidiano y otro festivo. En el primero -sobre todo en áreas rurales-, la alimentación se caracteriza por tener momentos matizados por su poca elaboración y, en el segundo caso, está definido por ser sumamente elaborado. Así, se conciben platos especiales que son exclusivos para los días de fiesta. 
De esta manera, en la parroquia rural Baños ${ }^{1}$ el conocimiento nutricio y la riqueza gastronómica expresa de manera tangible sus rasgos y saberes propios -caracterizados por las peculiaridades de la zona-, demostrados al momento de la representación de su comida dejando así entrever, a través de sus procesos culinarios, mucho de la cultura popular. En esta localidad encontramos recetas tradicionales como por ejemplo: timbulos, chaquis -o cuchichaquis-, empanadas de viento, chicha de jora, canelazo... Productos que han cambiado en el tiempo, tanto en su preparación como en su consumo.

De forma tradicional, parte de la cocina mencionada anteriormente, era elaborada y consumida -en mayor medida- por la gente que hacía romerías hacia El Cisne (Loja). Así, cierta cantidad de estos eran llevados al viaje y, la cantidad restante, la repartían entre los vecinos que llegaban a despedirlos. En la actualidad esta práctica subsiste en muy pocas familias.

El argumento expuesto problematiza la situación actual de la comida tradicional y de los denominados envueltos ${ }^{2}$ que, paulatinamente, están desapareciendo de la memoria gastronómica de la zona, pues la inmediatez en la alimentación ha provocado consumir "comida rápida" -aspecto que genera pérdida de dichas manifestaciones-. A su vez, el imaginario creado en torno a los envueltos lleva tras de sí una serie de tabús ${ }^{3}$ que fomentan, aún más, la desaparición de los productos.

Por ello, el presente artículo busca registrar y contextualizar las manifestaciones culinarias de la parroquia rural de Baños haciendo hincapié en la elaboración de los envueltos, productos considerados como patrimonio y memoria de la región. La metodología se fundamentó en la entrevista etnográfica a las actoras de la preparación de los envueltos (Imagen 1) y, conceptualmente, se justificó desde el entendimiento de la gastronomía como discurso patrimonial y cómo la alimentación trasciende la funcionalidad de nutrición hasta ser generadora de significados y emociones "que se encuentra ligado a circunstancias y acontecimientos que nada tienen que ver con la estricta necesidad de alimentarse" (Contreras, 1992: 102).

\footnotetext{
${ }^{1}$ Baños es una parroquia rural del cantón Cuenca, provincia del Azuay, Ecuador.

2 Por envueltos nos referimos a aquellos productos alimenticios que son elaboradas a base de harinas y que son cubiertos en hojas naturales como: hoja de maíz, huicundo y achira.

${ }^{3}$ Los timbulos y los envueltos, históricamente, en la parroquia Baños están asociados a una etapa de la historia donde familias de bajos recursos los consumían. Por ello, posiblemente, las generaciones actuales ven a estos productos como simples y oprobiosos.
} 
Imagen 1. Doña Estela Siguenza.

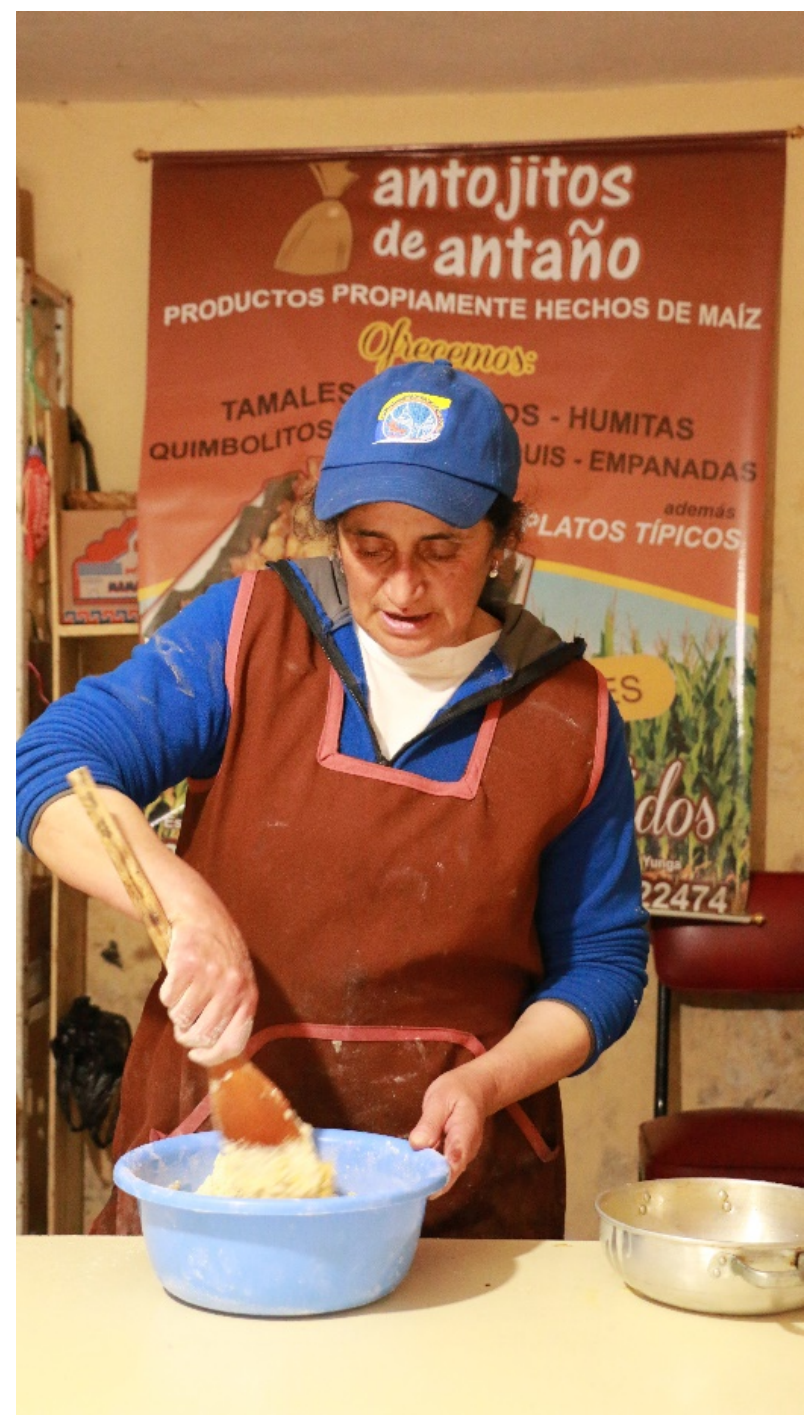

Foto: Miguel Novillo

\section{La cocina: patrimonio, identidad y memoria}

Generalmente el patrimonio se configura como la preservación de tradiciones propias de un lugar resaltando aspectos considerados como definidores e identificadores de un grupo (Malo, 1996). Para comprender las implicaciones culturales de la cocina en la región y la localidad -Baños-, es necesario proponer, discutir y reflexionar conceptos como patrimonio, identidad y memoria bajo una perspectiva histórica. 
El concepto de Patrimonio ha estado en permanente configuración en el tiempo, sin embargo, según la Organización de las Naciones Unidas para la Educación, la Ciencia y la Cultura (UNESCO) a partir de la institucionalización de las manifestaciones culturales, ha categorizado al Patrimonio Cultural como:

\begin{abstract}
Las tradiciones o expresiones vivas heredadas de nuestros antepasados y transmitidas a nuestros descendientes, como tradiciones orales, artes del espectáculo, usos sociales, rituales, actos festivos, conocimientos y prácticas relativos a la naturaleza y el universo, y saberes y técnicas vinculados a la artesanía tradicional ${ }^{4}$.
\end{abstract}

En tanto que, el Patrimonio Cultural Inmaterial "no solo incluye tradiciones heredadas del pasado, sino también usos rurales y urbanos contemporáneos característicos de diversos grupos culturales 5 ." En este sentido, en Ecuador la Ley Orgánica de Cultura expedida en el 2016, en su Art. 50 señala que:

Los bienes que conforman el patrimonio cultural del Ecuador son tangibles e intangibles y cumplen una función social derivada de su importancia histórica, artística, científica o simbólica, así como por ser el soporte de la memoria social para la construcción y fortalecimiento de la identidad nacional y la interculturalidad ${ }^{6}$.

Sobre el patrimonio intangible o inmaterial, el Art. 52, hace referencia a:

...todos los valores, conocimientos, saberes, tecnologías, formas de hacer, pensar y percibir el mundo, y en general las manifestaciones que identifican culturalmente a las personas, comunas, comunidades, pueblos y nacionalidades que conforman el Estado intercultural, plurinacional y multiétnico ecuatoriano ${ }^{7}$.

A partir de las concepciones propuestas por las leyes y normativas patrimoniales -nacional e internacional- reconocemos la amplitud de las definiciones $y$, consecuentemente, ciertas deficiencias y desavenencias que se manejan en el país en términos de cultura, patrimonio e identidad, puesto que, el desarraigo que se percibe en ciertas localidades y en los miembros de una colectividad en la cotidianidad, es inmenso y preocupante.

Ahora bien, por identidad nos referimos a la construcción social "donde los integrantes de una comunidad contribuyen con sus saberes, prácticas y narrativas al establecer parámetros para la comprensión de sí mismos" (Castillo,

${ }^{4}$ UNESCO, https://ich.unesco.org/es/que-es-el-patrimonio-inmaterial-00003. Última entrada: 28 de marzo 2018.

5 UNESCO, https://ich.unesco.org/es/que-es-el-patrimonio-inmaterial-00003. Última entrada: 28 de marzo 2018.

${ }^{6}$ Registro oficial, Ley Orgánica de Cultura 2016.

${ }^{7}$ Registro oficial, Ley Orgánica de Cultura 2016. 
Sanhueza y Corcuera, 2012: 54), por tanto ésta es un producto de la cultura en constante transformación. Al contrario, el Patrimonio es considerado como la síntesis simbólica de los valores identitarios de una sociedad que los reconoce como propios. Sin embargo, en sociedades no tradicionales las prácticas, tradiciones y costumbres pueden ser olvidadas generando un vacío o sesgo en sus bases (Santana, 1998). De esta manera -en varias ocasiones-, las acciones políticas aprovechan dicho sesgo para implantar un argumento patrimonial y su respectivo llamamiento a la memoria colectiva.

Las fuentes orales de la memoria local de esta parroquia se convierten en recursos necesarios e importantes para experimentar y construir una versión más plural y quizá más polifónica de lo que son las tradiciones. Los narradores particulares se inscriben en un ámbito colectivo, desde allí nutren su memoria y construyen su discurso en donde rememoran los núcleos de experiencia que sustentan sus identidades y sus pertenencias sociales. Los narradores son, por lo tanto, conductos hacia los temas y motivos de las memorias diversas en un pueblo (Portelli, 1989). En este sentido, las narrativas nos llevan a pensar la cocina, gastronomía y alimentación como dispositivos cargados de valores simbólicos y memoria.

La producción de alimentos responde a una especificidad cultural y social (Danforth, 1999; Hamilakis, 1999; Peláez, 1997) que no recae únicamente en la transformación y elaboración de comida a partir de instrumentos o técnicas específicas, sino también como un espacio socialmente significativo de la transformación.

A partir de esta instancia los gustos y disgustos ${ }^{8}$ por los alimentos se deben a múltiples causas e influencias como la herencia genética, la dieta materna, las prácticas, el aprendizaje, la cognición y la cultura infantil: "el desarrollo de las preferencias alimentarias puede ser un modelo ideal de la interacción de estos factores durante nuestro tiempo de vida" (Katz and Woys, 2003). Aspecto que sobresale en la parroquia Baños y la producción de su cocina.

\footnotetext{
${ }^{8}$ Como se observa, el empleo de la manteca de chancho es el principal producto para los envueltos, sin embargo, en ocasiones la cantidad de manteca es nula o poca, pues hay personas que no pueden consumir este producto, por ende piden que no se prepare los envueltos con manteca. De esta manera, la manteca es reemplazada por aceite, pese a ello, el sabor cambia pero mantiene la textura. Otros pedidos han sido no utilizar, por ejemplo, clavo de olor pues es muy fuerte, o el anís ya que le han dicho que les hace daño, por ello, se utiliza solo canela y pimienta de dulce.
} 


\section{Los envueltos de Baños}

Como se mencionó anteriormente es basta y variada la gastronomía que se elabora en la parroquia Baños. En este caso, serán descritos los alimentos procesados con harina de maíz, harina blanca, entre otros y, que son envueltos en hojas naturales como mazorca, achira o huicundo. Entre estos tenemos: timbulos, chaquis, tamales, quimbolitos y humas. Estos productos se caracterizan por tener un tratamiento particular $y$, un proceso de elaboración específico.

Un primer producto, el timbulo (Imagen 2), se caracteriza por ser un bocadillo que no puede faltar en las fiestas del 8 de septiembre. Vendedoras de distintos sectores de la parroquia -sobre todo de Narancay-, acudían (y acuden) a la plaza central a comerciar sus productos. Años atrás, los timbulos fueron infaltables los días domingos, después de misa de la mañana. En este contexto surgen las figuras de Doña Rosa Arpi y Estela Siguenza -llevan más de 40 años elaborando envueltos-, quienes recrean esta actividad:

“...antes era bien sacrificado hacer los timbulos y se hacían solo para las fiestas, no durante todo el año como lo hacen ahora. Antes nosotras para hacer los timbulos teníamos que esperar el tiempo de cosecha del maíz".

Rosa Arpi, cocinera (65 años).

Imagen 2. Envuelto conocido como timbulo.

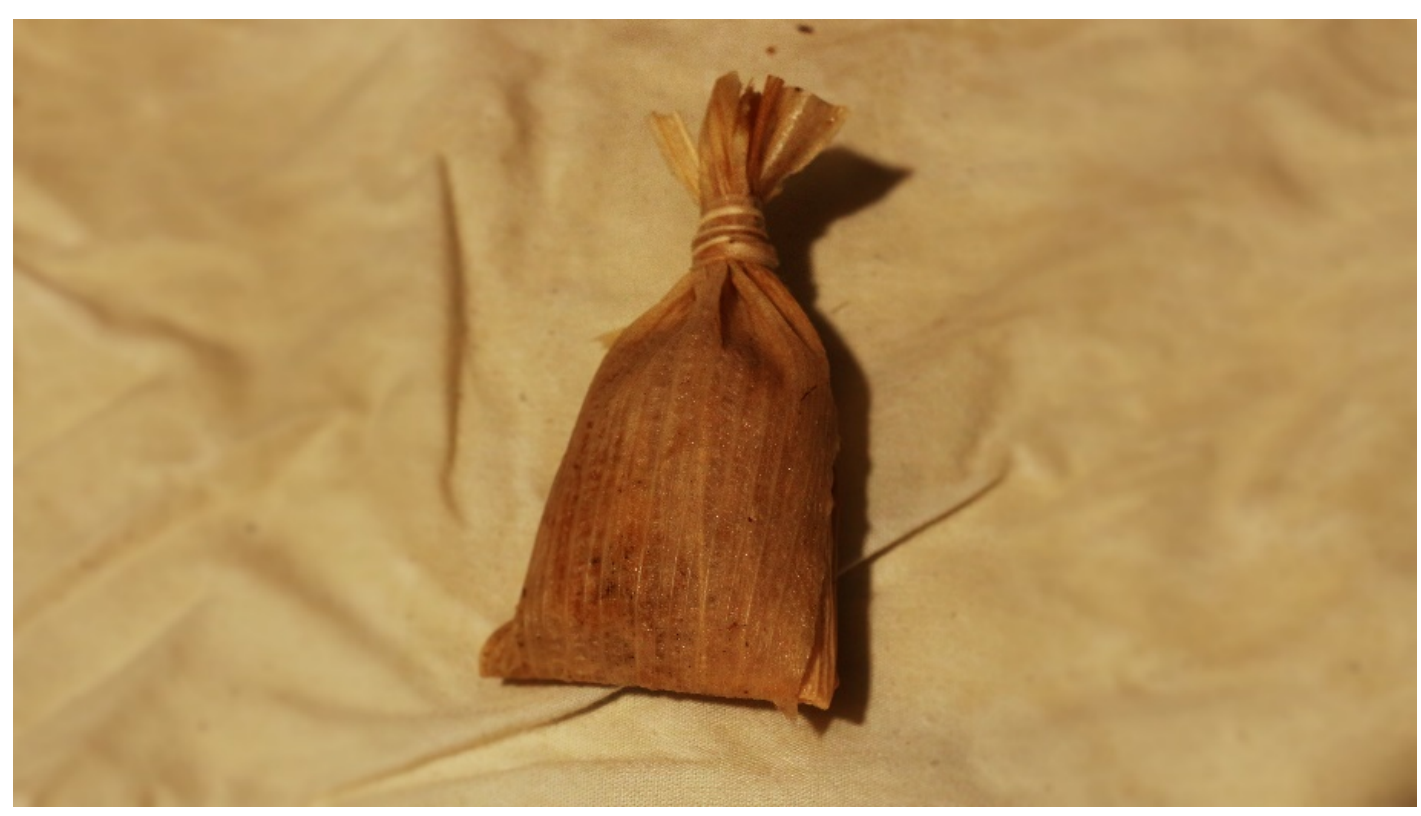

Foto: Miguel Novillo 
La producción de timbulos -y envueltos en general- nos lleva a hablar de categorías como roles y paisaje. El primero, remite a los papeles específicos que se designan para la siembra, la cosecha, la preparación de la tierra y la transformación de la materia prima en alimento, actividad que implica la participación de varios agentes:

\begin{abstract}
Nos íbamos todos de la casa, mamá, papá, hijos, y también se rogaba a los primos, tíos, vecinos. A veces nos demorábamos dos días cosechando el maíz (...). Cuando terminábamos de cosechar nos tocaba deshojar el maíz, y mientras deshojábamos íbamos escogiendo los pucones más buenos para después hacer los timbulos. Cada quien llevaba un poco de pucón a sus casas para ponerle a secar y que se caiga el gusano. Mientras se secaba el pucón, en casa molíamos el maíz, era bien cansado por eso también participábamos bastantes personas.
\end{abstract}

Estela Siguenza, cocinera (60 años).

En cambio el paisaje, configura la arquitectura y las actividades de las personas. Por un lado, las casas de adobe y teja se ven enlucidas por grandes extensiones de sembríos de maíz. Los maizales constituyen espacios de interacción entre los miembros de la comunidad quienes, aquí, escogen el maíz en su estado maduro o tierno: "... eran pampas grandes, a veces cogíamos en choclo para hacer un poco de golosinas. Pero la cosecha grande se hacía cuando ya estaba maduro..." (Estela Siguenza, 60 años). Una vez culminada la cosecha de maíz se continúa con la preparación.

Los timbulos o bañonejos son preparados con harina de maíz blanco o amarillo, panela, queso, manteca de chancho, mantequilla, canela. La harina es mezclada con agua de la panela hervida con canela a vapor. Al agua dulce se le incorpora la harina hasta obtener una masa que es tratada con manteca de chancho.

Posteriormente, se coloca en la mitad queso con panela rallada (Imagen 3). Finalmente se envuelve en el pucón -hoja de la mazorca madura- y se la cocina: "ya con el pucón seco, el maíz molido, sólo comprábamos queso y panela" (Estela Siguenza, 60 años). Este proceso está en constante cambio por diferentes causas como: la adquisición de materia prima -antes era sembrada y cosechada por las cocineras, ahora se compra el maíz-; desaparición de roles y actividades, en la actualidad se utilizan maquinarias para el arado o simplemente las tierras han cambiado de uso; cambio de propiedad de la tierra donde se sembraba el maíz, tal como lo afirma Estela Siguenza:

“...compramos el maíz molido, también el pucón, porque ya no hay donde sembrar el maíz; las tierras están repartidas a herederos, ni tenemos quien nos ayude."

Estela Siguenza, cocinera (60 años). 
Imagen 3. Preparación de timbulos o bañonejos.

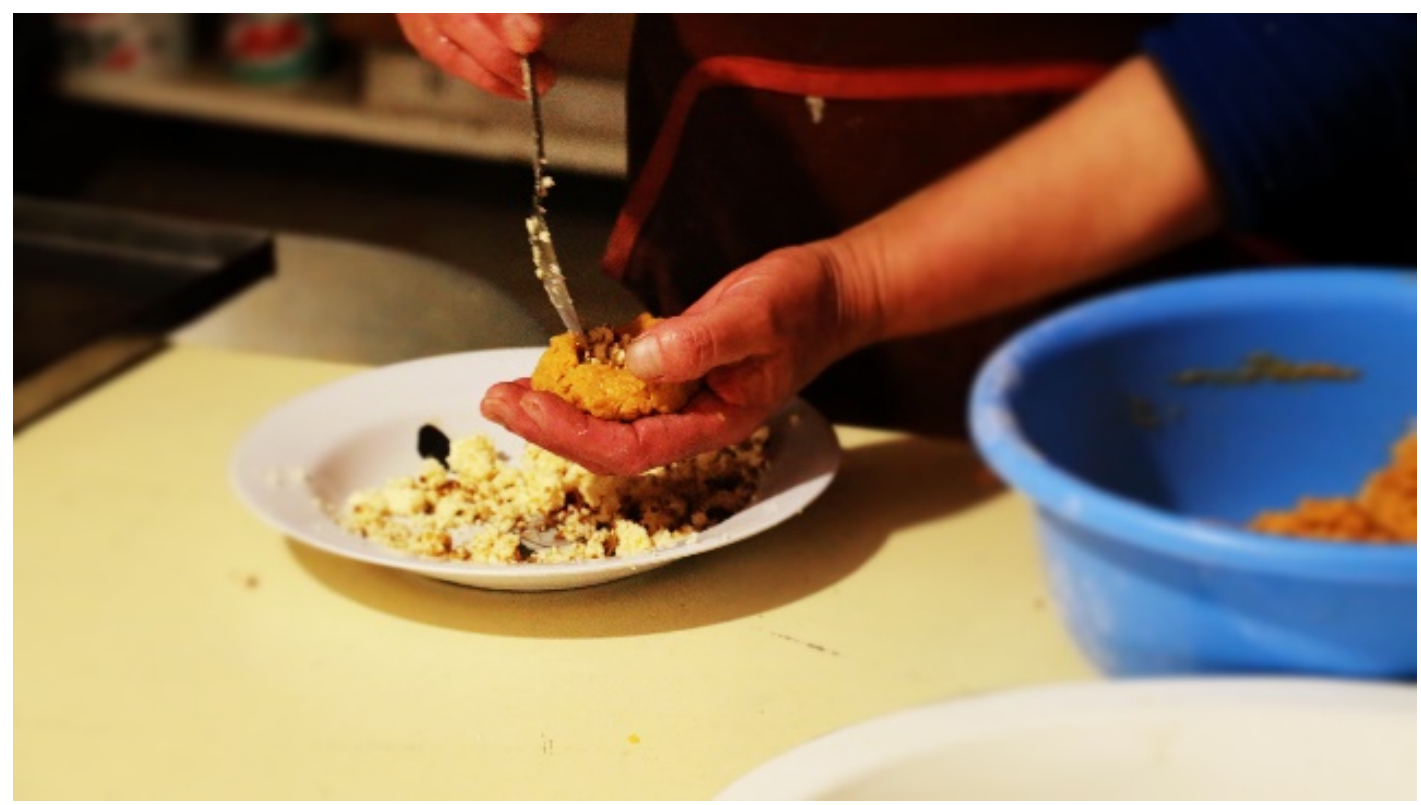

Foto: Miguel Novillo

El segundo envuelto característico de Baños lo representa el chaqui. Este, en un principio, era elaborado para obsequiar a las personas que iban de romería. A cambio, los romeriantes como acto recíproco, traían dulces tradicionales de El Cisne, Loja.

Los chaquis (Imagen 4) son elaborados con harina de maíz pelado, sal, manteca de cerdo, especerías, queso o carne de cerdo. Se hierve el agua con la carne, sal y especerías; luego se mezcla con harina y se amasa con la manteca, pues le brinda a esta suavidad. Cuando está blanda la masa se hacen bolas y en la mitad se introduce queso. Para terminar se envuelve en hojas de huicundo y se cocina.

Otro envuelto característico son las humitas o chumales. Estas son preparadas en época de choclos -marzo-mayo-, pues si se los prepara en un tiempo diferente o si se compra el maíz del norte del país, estos no tienen el mismo sabor. En su preparación participa toda la familia:

"se necesita de varias manos para ahorrar tiempo. Los mayores se encargan de buscar los choclos, los muchachos tienen que deshojar, separar los pucones buenos, otros desgranan y muelen el choclo. Para moler se necesita de hombrecitos."

Estela Siguenza, cocinera (60 años). 
Imagen 4. Preparación de chaquis.

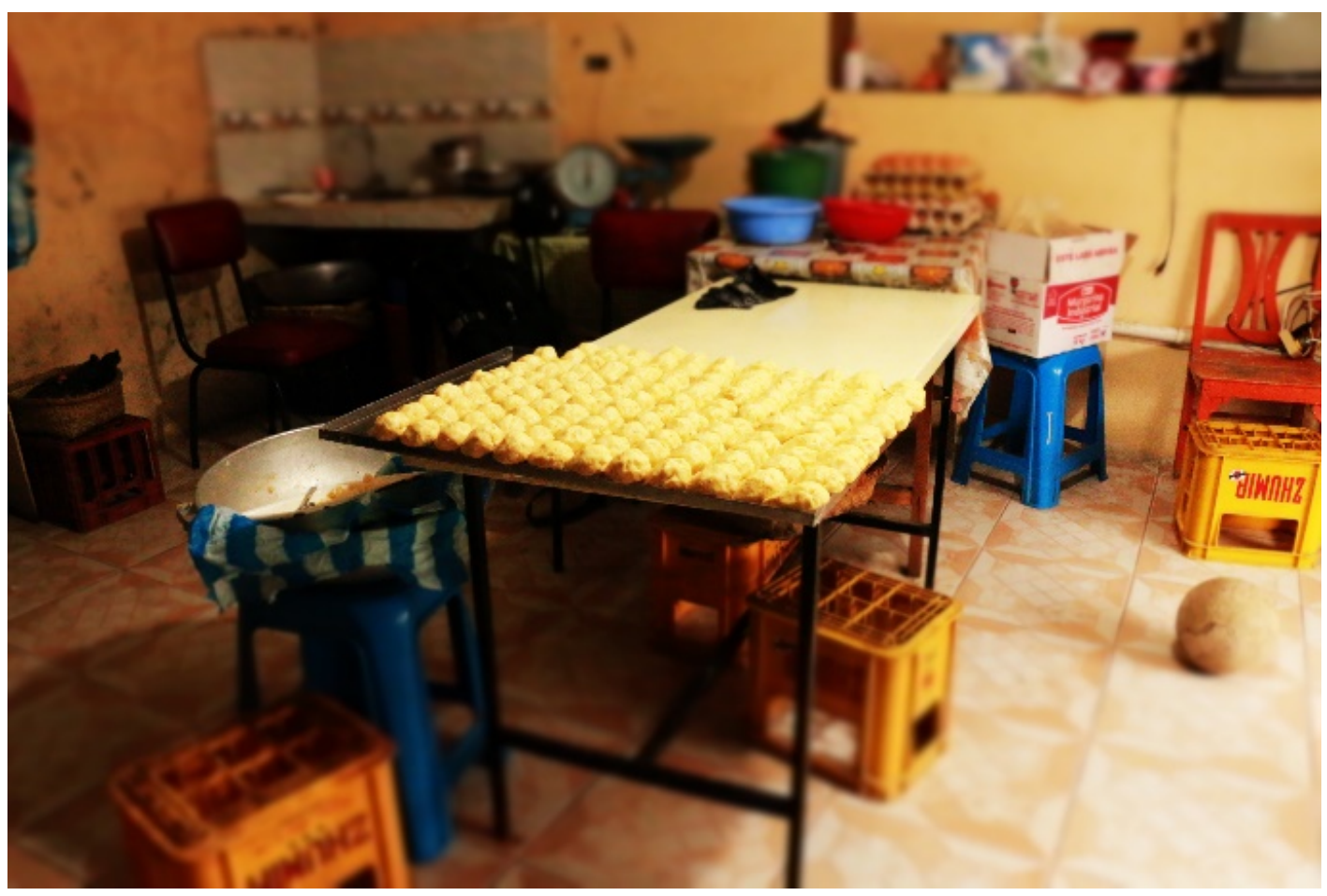

Foto: Miguel Novillo

Las humitas se preparan con choclo tierno y maduro, cebolla colorada y blanca, anís, mantequilla, manteca, royal-opcional-, azúcar y sal, queso, hojas de choclo tierno. El primer paso es moler el choclo y las cebollas. Se mezcla el contenido con anís, manteca, sal y azúcar. Se consolidan los ingredientes en una masa no dura ni aguada. Luego se adhiere queso en el centro, se envuelve en hojas de maíz y se las cocina.

Con harina amarilla, carne de cerdo o pollo, pimiento, huevos, pasas, manteca de cerdo, cebolla colorada, sal, manteca de color, arveja, zanahoria-opcional-y hojas de achira se elaboran los denominados tamales.

Para elaborar el tamal se cocina la carne en agua obteniendo un caldo, al que se le agrega especerías, manteca, sal y manteca de color. Se mezcla la harina con el agua, la manteca y las especerías hasta que quede una masa firme. Aparte se prepara el condumio -se fríe la carne, arveja y zanahoria, además de adherir rodajas de huevo-. Para terminar se coloca el condumio en la mitad de la masa, se los envuelve en las hojas de achira y se cocina. 
En cambio, los quimbolitos son elaborados con harina de castilla y harina de maíz (Imagen 5), azúcar, pasas, hojas de achira, leche, huevos, mantequilla, royal y queso. Su preparación consiste en combinar la harina con la mantequilla, se añade leche tibia, huevos batidos, royal y azúcar. Se espolvorea con queso rallado. Se mezclan bien los ingredientes hasta formar una masa homogénea para finalmente colocar la masa en las hojas de achira.

Imagen 5. Harina de castilla y maíz listo para ser molido.

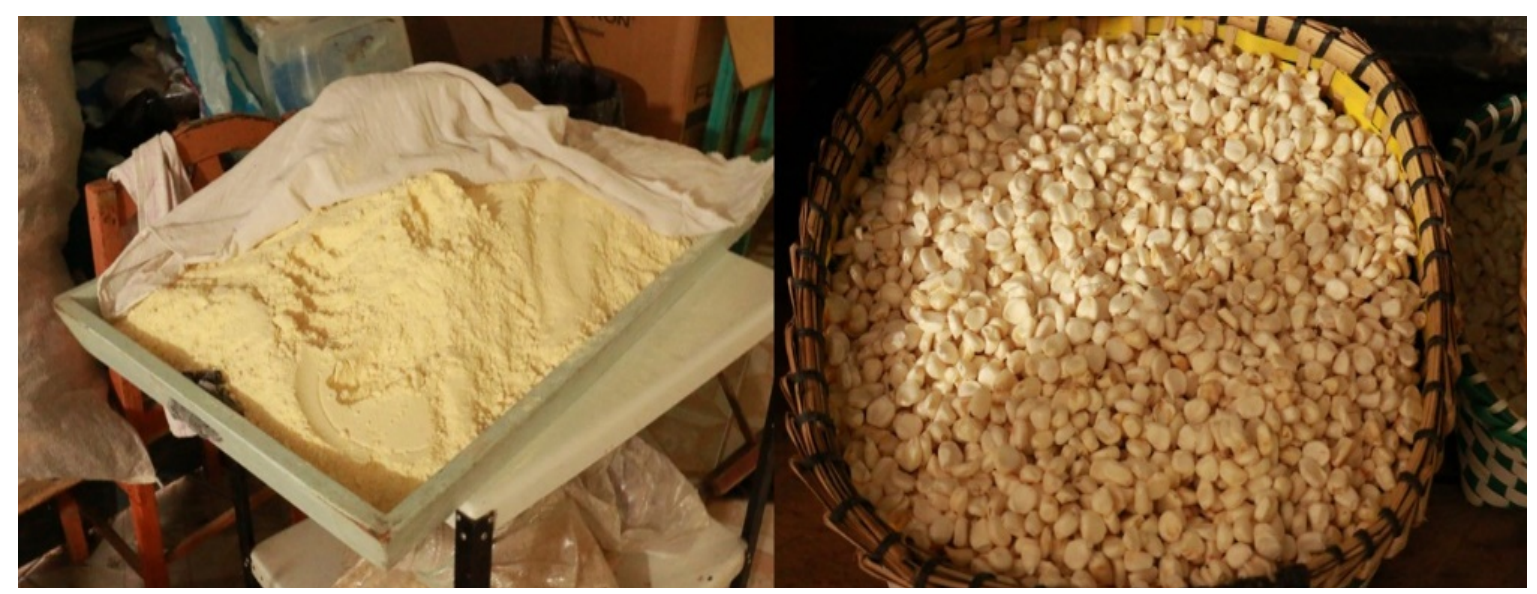

Foto: Miguel Novillo

Los envueltos descritos hasta el momento son puestos a la venta los fines de semana. Se ofrecen, aproximadamente, 1000 unidades: 300 timbulos, 200 chaquis, 150 humas, 180 quimbolitos, 120 tamales. Los cerca de 1000 envueltos son vendidos en un lapso de 4 horas. Además, en ocasiones, acude gente de otras localidades o diferentes partes, quienes hacen pedidos, por ejemplo desde Guayaquil: "me piden el número de cuenta, me depositan, yo preparo los envueltos y les mando por una empresa de transporte" (Rosa Arpi, 65 años).

Existen otras personas que, por diferentes circunstancias, vienen a la ciudad. Antes de retornar a sus lugares de origen hacen el pedido y se llevan gran cantidad de productos. Inclusive, disponen de una clientela que trasciende fronteras pues, familiares envían la comida hacia los Estados Unidos. Últimamente se trabaja con una hostería, con la diferencia que al ser un local pensado para ocasiones especiales o para el turismo, las porciones que se realizan son pequeñas. Aquí se toma el argumento de la gastronomía como institución. 
Un elemento fundamental para la elaboración de envueltos -que le da su nombre a esta variedad gastronómica- lo constituyen las hojas (Imagen 6) que cubren las masas y pueden ser de maíz, de achira y de huicundo. Estas últimas, antiguamente, eran recolectadas y traídas desde los bosques por la familia o por trabajadores. En la actualidad se compran en el mercado. De igual manera, antes muchas personas tenían en sus huertos hojas de achira para envolver el tamal. No obstante, ahora ya no se tiene esta planta en las cercanías de las viviendas por ende no se abastece la producción de tamales.

Imagen 6. Variedad de hojas para envueltos: maíz, achira y huicundo

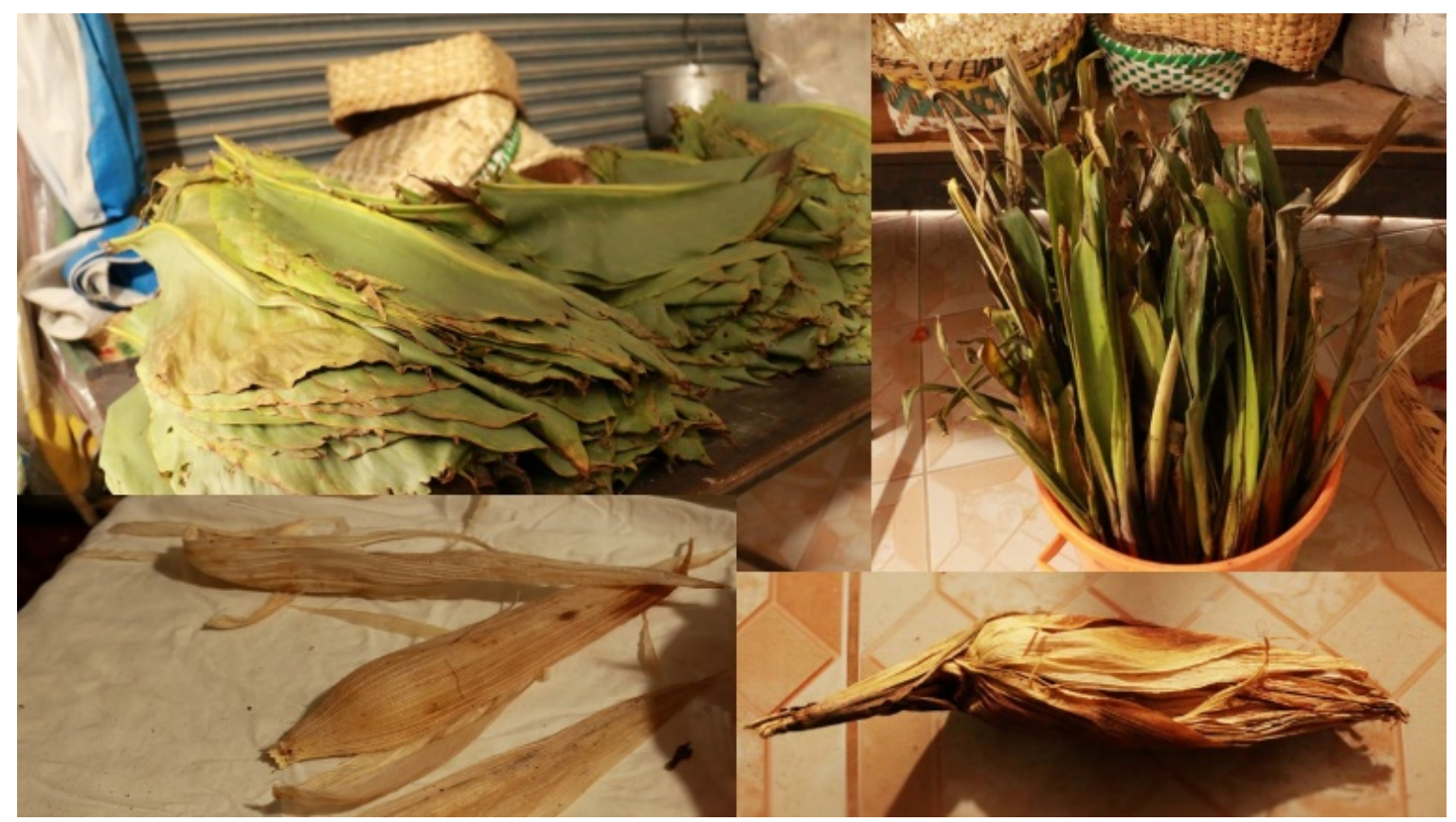

Foto: Miguel Novillo

Las hojas tienen que ser recogidas en tiempos de cosecha, por ello -y para darse abasto- se solicita a los vecinos que guarden las hojas y que las vendan a las cocineras. Quienes compran en grandes cantidades y las guardan en sacos para todo el año pues, también existen temporadas de fuertes lluvias y con ello la pérdida de las hojas, primordialmente de pucón -hoja que es seleccionada ya que existen pucones de color negro que no sirven para el preparado-. 
La hoja de huicondo tiene que estar bien lavada y puesta en remojo. Existen dos tipos de hojas de huicundo, una que despide un sabor amargo y por ello no sirve para preparar los chaquis: "A veces yo también caigo. Los clientes me dicen oiga han estado amargas, sí me reclaman a veces" (Rosa Arpi, 65 años). Un truco para limpiarlas de forma adecuada y quitar el amargo de las hojas es meterlas en agua caliente, lavarlas y secarlas, para finalmente seleccionar las que no estén dañadas. Nunca se ocupa toda la hoja, sino, las que están adentro del racimo las primeras hojas son botadas-.

\section{Reflexiones finales}

En la actualidad se percibe un decaimiento de la denominada cocina y gastronomía tradicional -envueltos en la parroquia Baños- que, antiguamente, constituía un elemento identitario, cotidiano y de trascendental importancia para la comunidad. Si bien la producción y consumo de los envueltos ${ }^{9}$ sigue vigente en distintas esferas de la sociedad-como por ejemplo locales ofertados para el turista-, esta ha cambiado de actores, roles, recursos y usos. Así por ejemplo, años atrás las masas de maíz "se envolvían en hojas y se cocinaban en agua. En la cocina tradicional estas masas se han enriquecido con huevos, manteca, mantequilla, quesos, pasas, etc..." (Pazos, 2017: 48), es decir, con el transcurrir del tiempo se han agregado nuevas tecnologías y diversos ingredientes.

De igual manera, para la elaboración de humas, tamales, chaquis y timbulos o bañonejos ${ }^{10}$ se requería la participación de familiares, vecinos y trabajadores. Era una actividad colectiva ${ }^{11}$, donde cada miembro cumplía una función

\footnotetext{
${ }^{9}$ La elaboración de los envueltos, antiguamente, obedecía a un contexto familiar ya que el pan era caro y escaso para la población -considerado un artículo de lujo-: "El pan se compraba solo cuando iba mamá a la feria, ya venía trayendo el pan del centro de la ciudad. Como lujo, o sea cada viernes, a veces viernes y sábado, que a veces hacíamos durar ¡como éramos bastantes!" (Estela Siguenza, 60 años).

${ }^{10}$ Generalmente, la comida en la historia ha tenido momentos de aceptación y otros de negación. Así, en la actualidad, el timbulo no es un producto de alta demanda en la ciudad, frente a las humas y tamales: "A veces les vendo los tamales, las humas y yo les digo les voy a mandar una yapita y les pongo un timbulo" (Rosa Arpi, 65 años).

11 Estela Siguenza (60 años) a este respecto señala: "Nosotros hacíamos bastante, unas 400, unas 500 timbulos- y como éramos bastantes, éramos como 15 que tomábamos café; antes eran 30 por comida y mamá como era así por los trabajadores, sabía decir para que tengan voluntad de trabajar. Ella les atendía bien. A ella le pedían que les dé cocinando el zambito y el zapallo. Antes como se trabajaba, se sembraba el maíz todo con gente, entonces a la gente le gustaba trabajar cuando sabia estar bien atendido".
} 
específica: siembra, cosecha, molido ${ }^{12}$ y preparación de masas, recolección y limpieza de hojas...

\begin{abstract}
La mamá elaboraba los envueltos para consumo familiar, que era muy numerosa nueve hermanos de sangre y tres hermanos de crianza-. La actividad agrícola, complemento de muchas familias tiempo atrás, implicaba la confluencia de gente ajena al contexto familiar, sin embargo, esa gente también era parte de la compartición de alimentos. Así, su madre hacía tamales, humas, chaquis, timbulos y quimbolitos, para tomar el café de la mañana y el conocido café de la tarde.
\end{abstract}

Estela Siguenza, cocinera (60 años).

En este sentido la cocina, la gastronomía y la alimentación son manifestaciones que permiten escudriñar en las relaciones sociales y en los múltiples tejidos que las constituyen, pero sobre todo, son maneras de decir quiénes somos. Si bien los seres humanos y muy pocos animales hemos desarrollado la capacidad para digerir una gran cantidad de alimentos de diversas naturalezas, sin embargo, somos nosotros la única especie que pensamos y hablamos acerca de sus alimentos; los únicos que manejamos normas y reglas con respecto a lo que comemos; a su modo de preparación y a sus formas de consumo; además, de elegir con quién o quiénes y dónde degustamos un platillo.

Asimismo, organizamos nuestras ingestas, comidas o acontecimientos alimentarios, más o menos socializados y estructurados. Es decir, los alimentos, no son simples portadores de energía y de nutrimentos, sino que están llenos de significados que, según Mintz (2003), son atributos que les confiere una población para clasificarlos de tal forma que guían su elección según la edad, el sexo, la condición socioeconómica, el momento, la ocasión, la imagen, entre muchos otros factores.

Así, la cocina estrecha las relaciones sociales, pues la alimentación no es, exclusivamente, un fenómeno biológico, nutricional o médico, es, además, un evento social, psicológico, económico, simbólico, religioso. Esto es cultural en el más amplio sentido del término. Ignorar esas correspondencias puede provocar la incomprensión o una comprensión incorrecta o incompleta de determinados comportamientos alimenticios.

La relación cocina, memoria y patrimonio nos refiere a la construcción de ideas, pensamientos e imaginarios que la cultura mantiene con las memorias públicas, es tan íntima y recíproca a la vez que, a falta o falencia de conceptualizaciones,

\footnotetext{
${ }^{12}$ Antiguamente se utilizaban distintos medios para moler el maíz. En la actualidad, la molienda se la realiza en una máquina de moler, o en su defecto, se compra en el mercado el maíz molido.
} 
todo un complejo sistema de entendimiento cultural surge para catalogar a tal o cual bien como patrimonio.

Finalmente, en el mismo lineamiento, Manuel Espinosa Apolo, se refiere a dos funciones vitales y trascendentes de la tradición (aspecto de la cultura inmaterial), sea como transmisora de experiencias previamente seleccionadas y almacenadas que viabilizan y contribuyen a optimizar la adaptación a un medio histórico y natural determinado; en segundo elemento, vinculado a la mantención de la estabilidad y la reproducción de la sociedad como sistema específico poseedor de una singularidad fisiognómica (2008: 92). 


\section{BIBLIOGRAFÍA}

Castillo, C.; Sanhueza, M. \& Corcuera, E. (2012). Identidad y memoria histórica del tejueleo artesanal: un oficio maderero en riesgo de extinción en la región de Aysén. Conserva 17, 53-67.

Contreras, J. (1992). Alimentación y cultura: reflexiones desde la Antropología. Revista chilena de Antropología 11, 95-111.

Danforth, M. E. (1999). Nutrition and Politics in Prehistory. Annu. Rev. Anthropol. $28,1-25$.

Espinosa, M. (2008) Los mestizos ecuatorianos. Quito: Editorial Ecuador.

Hamilakis, Y. (1999). Food Technologies/Technologies of the Body: The Social Context of Wine and Oil Production and Consumption in Bronze Age Crete. World Archaeology. 31 (1), 38-54.

Hayden, B. (2003). Were Luxury Foods the First Domesticates? Ethnoarchaeological Perspectives from Southeast Asia. World Archaeology 34 (3), 458-469.

Katz, S. \& Williams W. (2003). Encyclopedia of Food and Culture. Katz, S. \& Williams, W. (eds.). Acceptance a Food Politics. Estados Unidos.

Malo, C. (1996). Arte y Cultura Popular. Cuenca: CIDAP.

Mintz, S. (2003). Sabor a comida, sabor a libertad. Incursiones en la comida, la cultura y el pasado. México: Ediciones de la Reina Roja.

Naranjo, M. (2005). La Cultura Popular en el Ecuador, Carchi. Tomo XII. Cuenca: CIDAP.

Pazos, J. (2017). Elogio de las cocinas tradicionales del Ecuador. Ecuador: Centro de publicaciones, Pontificia Universidad Católica del Ecuador.

Peláez, M. (1997). Consideraciones teóricas. Peláez, M. (comp.). Presencia de la antropología en los estudios sobre alimentación. México: Cuadernos de Trabajo 
IIA, Instituto de Investigaciones Antropológicas, Universidad Nacional Autónoma de México: pp. 13-21.

Portelli, A. (1989). Historia y memoria: la muerte de Luigi Trastulli._Historia y Fuente Oral 1, 5-32.

Santana, A. (1998). Patrimonio cultural y turismo: reflexiones y dudas de un anfitrión. Revista Ciencia y Mar 6, 37-41.

\section{ENTREVISTAS}

Doña Rosa Arpi, cocinera de envueltos, Miguel Novillo y Elsa Sinchi, enero 22, 2018.

Doña Estela Siguenza, cocinera de envueltos, Miguel Novillo y Elsa Sinchi, febrero 02, 2018. 
Revista Herencia, Vol. 31 (2), julio-diciembre, 2018. 